\title{
Study of the nature of the dynamic coefficient of internal friction of grainmaterials
}

\author{
Dmitriy Savenkov ${ }^{1, *}$, Oleg Kirischiev ${ }^{1}$, Ylia Kirischieva ${ }^{1}$, Tatiana Tupolskikh ${ }^{1}$, Tatiana \\ Maltseva ${ }^{1}$, Magomed Magomedov ${ }^{1}$, and Andrey Chistyakov ${ }^{1}$ \\ ${ }^{1}$ Don State Technical University, Rostov-on-Don, Russian Federation
}

\begin{abstract}
The article highlights the issues related to the study of physical and mechanical characteristics of bulk materials, namely internal friction coefficients in static and dynamic modes. An innovative device of the carousel type for determining the frictional characteristics of bulk materials is described, which allows to implement the tasks of practical determination of dynamic coefficients of internal friction. Presented the program, methodology and results of research on the practical study of the internal friction coefficient of typical bulk products of agricultural production in the range of linear velocities of displacement of layers from 0 to $2.79 \mathrm{~m} / \mathrm{s}$, the reliability of which is not lower than 0.878 .
\end{abstract}

\section{Introduction}

At design and operation of agricultural machines it is necessary to consider physical and mechanical properties of grain crops with which working bodies of machines directly interact. One of the indicators characterizing these properties is the coefficient of friction of grain crops, since its value affects, for example, the process of unloading grain materials from bunkers [1-4].

Friction is one of the most common physical phenomena in agriculture. In this regard, the determination of frictional characteristics of bulk materials is an urgent task.

When a body slides on any surface, its movement is hindered by the friction force of the slide

$$
\mathrm{F}=k \cdot N
$$

where $\mathrm{N}$ - the reaction force of the support (the weight of the bulk material), $\mathrm{N} ; \mathrm{k}$ dimensionless coefficient of sliding friction [5-9].

The sliding friction force is always directed opposite to the movement of the body. When the direction of the velocity changes, the direction of the friction force also changes.

The values $\mathrm{F}$ and $\mathrm{N}$ can be measured by different methods in the course of practical studies, which allows to calculate the coefficient of friction

$$
k=\frac{\mathrm{F}}{N}
$$

There is a wide variety of installations for determining the frictional characteristics of

\footnotetext{
* Corresponding author: savenkov-dstu@yandex.ru
} 
bulk materials, which are based on three main methods of measuring the coefficient of friction (the inclined plane method, the "mound" method and the "torsion" method»). Based on the analysis of such installations, it can be concluded that the speed range in which the dynamic coefficient of friction was determined does not exceed $0.215 \mathrm{~m} / \mathrm{s}$. However, in real grain processing machines, the speed of movement of bulk material by the working body can reach up to $15 \mathrm{~m} / \mathrm{s}$ and more.

The aim of the study is to identify the nature of the dependence of the dynamic coefficient of friction on the rate of mutual displacement of layers of bulk products of agricultural production.

\section{Materials and methods}

To achieve the purpose of the study an innovative device for determining the frictional characteristics of bulk materials was designed and manufactured [10-15].

Figure 1 shows a General view of the device for determining the effect of the velocity of displacement of layers on the coefficient of dynamic friction of bulk products.

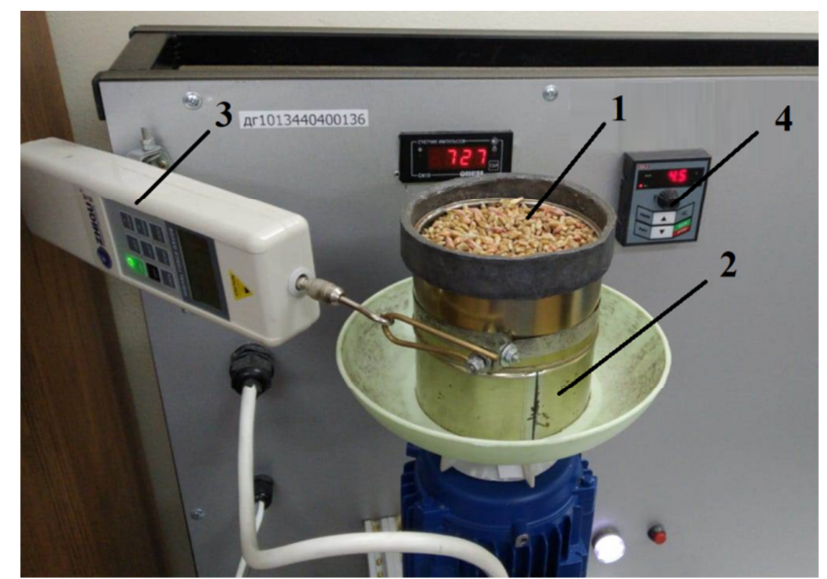

Fig. 1. The general view of the device to determine the effect of the layer displacement rate on the dynamic friction coefficient of bulk products. 1 - holder of friction device; 2 - cup; 3 - dynamometer; 4 - the regulator of speed of rotation of the cup

The main task performed by the device - ensuring the accuracy of the results of investigations of the friction characteristics of bulk materials: the coefficient of internal static friction and the coefficient of internal friction of the movement of one bulk material, the coefficient of mutual friction of rest and friction of motion of different bulk materials, as well as coefficient of static friction and coefficient of friction of different bulk materials on various hard materials.

To form a contact surface, the cup has an inner ring stage on which the holder rests. This device is guaranteed to shift and measure the shear force in the gap between the rotating cup and the cage by eliminating uncontrolled shear of material relative to the cage.

The bulk material is poured into the cup and then into the cage, thus forming a contact surface between the samples. The fixed cage is connected to the dynamometer, which has a digital panel to display the values of the force of interaction of the layers.

The linear velocity of the relative displacement of the layers is determined by the angular velocity [2]. 


$$
V=\frac{2 \pi R}{T}=2 \pi R v
$$

where $v$ - cup rotary speed, $\mathrm{s}^{-1} ; \mathrm{T}$ - the period of rotation of the cup, $\mathrm{s} ; \mathrm{R}$ - the inner radius of the cup, $\mathrm{m}$.

The final stage of development of the installation was the investigation of the dependence of effort on the dynamometer from speed of cup without of the investigated material - the efforts of the idling installation.

The aim of the study is to develop a method of making an absolute correction to the measured force in determining the dynamic coefficient of friction of bulk materials due to the design of the installation. The correction is necessary to account for its own friction in the load element of the installation, consisting of a cup and a cage. The correction is determined in the form of the force on the dynamometer at a given speed of rotation of the cup, loaded only by the own weight of the cage.

The task of the study is to build a mathematical model of the dependence of the force on the dynamometer on the rotation speed of the Cup.

The research method consisted in measuring the force on the dynamometer with a discrete change in the rotation frequency of the cup followed by mathematical processing of the results.

In the course of the research the following results were obtained, table 1:

Table 1. Static and dynamic friction coefficients for idling.

\begin{tabular}{|c|c|c|}
\hline Test & Rotational speed, $\mathrm{m}^{-1}$ & The force on the dynamometer, $\mathbf{N}$ \\
\hline 1 & 0,003 & 0,9 \\
\hline 2 & 0,62 & 1,1 \\
\hline 3 & 1,33 & 1,22 \\
\hline 4 & 1,75 & 1,2 \\
\hline 5 & 2,15 & 1,23 \\
\hline 6 & 2,51 & 1,2 \\
\hline
\end{tabular}

According to table 1, single-factor linear and power-law models of the dependence of the force $(\mathrm{y})$ on the rotational speed $(\mathrm{x})$ are constructed by means of the application "Diagrams" of the software complex "Microsoft EXCEL".

As a result of modeling the following dependences are obtained, figure 2: 


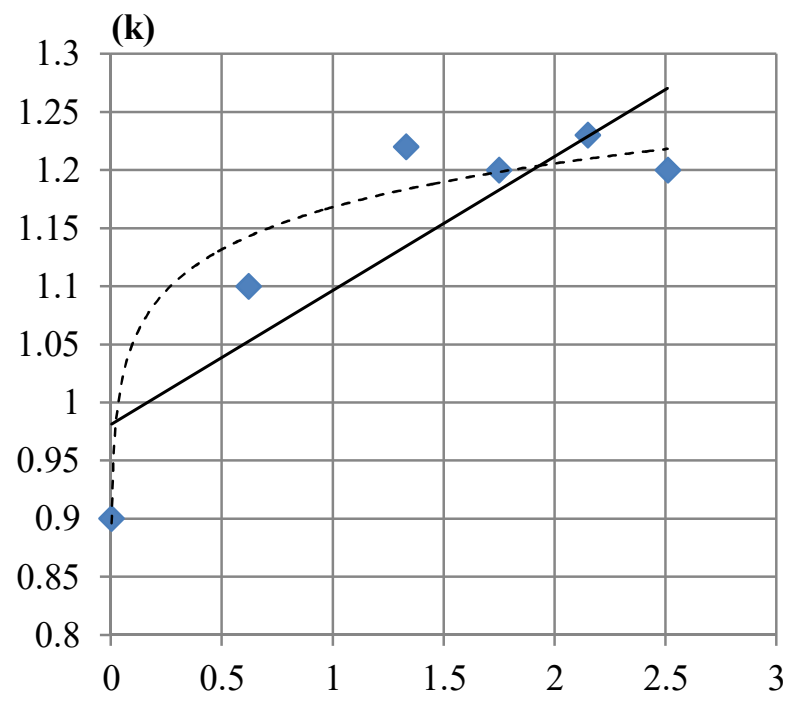

$$
\begin{gathered}
\mathrm{k}=\mathrm{f}(\mathrm{V}) \\
\text { linear } \\
\mathrm{y}=1.1681 \mathrm{x}^{0.0457} \\
\mathrm{R}^{2}=0.9599 \\
\mathrm{y}=0.115 \mathrm{x}+0.981 \\
\mathrm{R}^{2}=0.735
\end{gathered}
$$

(v), m/s

Fig. 2.Change in the dynamic coefficient of friction at idle.

The power-law function is used as a model for calculating the absolute correction

$$
\mathbf{y}=0,895 x^{0,062}
$$

The choice of the function type is carried out from the condition of maximization of the coefficient of determination $\mathrm{R}^{2}$.

\section{Results}

The developed plant is used for experiments to determine the nature of the dynamic coefficient of friction of the most typical grains and oilseeds with a similar seed shape:

- grain crops-wheat, barley;

- oilseeds-sunflower, safflower.

The calculation of the coefficient of friction is determined from the conditions of shift force application to the center of gravity $(\mathrm{M})$ simple sector of holder, limited rotation center of the Cup (O), arc shell ring and two radii (r), as shown in figure 3. The radius of the center of gravity - L. This takes into account the radius of the application point of the dynamometer force $(\mathrm{R})$.

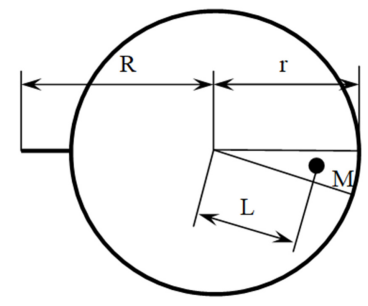

$$
\mathrm{R}=60 \mathrm{~mm}, \mathrm{r}=50 \mathrm{~mm}, L=\frac{2}{3} r
$$

Fig. 3. Determination of the radius of rotation of the center of mass of the material in the cage.

The methodology of the experiments:

1. A portion of the test material is loaded into the Cup to the level of the cage partitions. 
2. A measured portion of the test material weighing $m$ is filled into the holder.

3. The Cup rotation drive is activated.

4. A certain speed $n$ is set.

5. The force on the dynamometer (Y) is measured at least 3 times in 30 seconds and the results are recorded in the $\log$.

Measurements begin at the moment corresponding to the initial shift of the Cup. In this case, the shear force corresponding to the zero displacement velocity is measured, which allows the static coefficient of friction to be calculated. Further, the experiments are carried out at discrete values of the speed of rotation of the Cup, which are set based on the design capabilities of the installation. The maximum speed achieved during the experiments is 800 min-1, which corresponds to a linear velocity of $2.79 \mathrm{~m} / \mathrm{s}$.

Upon completion of the experiments for each grain product the following procedures are carried out:

1. The average value of the force on the dynamometer $(\mathrm{Y})$ is calculated.

2. The idle speed force correction of the unit is made using the model (1) and the force on the dynamometer $(\mathrm{T})$ associated with friction is determined.

3. The friction force $(\mathrm{F})$ is calculated from the condition of balancing the moment of friction force by the moment of force on the dynamometer

$$
F L=T R
$$

from what

$$
F=T \frac{3 R}{2 r}
$$

4. The linear velocity $(\mathrm{V})$ of the center of mass of the material portion is calculated.

5 . The value of the dynamic coefficient of friction $(k)$ for each velocity is calculated by the formula:

$$
k=F / N
$$

where: $\mathrm{N}$ is the gravity of the portion of material in the cage, $\mathrm{g}$ is the acceleration of free fall.

6. Linear and nonlinear models of dependence $k=f(V)$ for each material are constructed

7. The obtained dependencies are analyzed by comparing the values of $R^{2}$ and as a result the model with the maximum value of $\mathrm{R}^{2}$ is chosen. which is taken as a function describing the dependency $k=f(V)$ for the corresponding material.

8. In order to obtain information about the change of tribological characteristics of bulk products in dynamics in a more familiar form for the user, the internal friction angles $(\varphi)$ for each product are calculated according to the known formula:

$$
\varphi=\operatorname{arctg}(k)
$$

\section{Discussion of the results}

The results of experiments to determine the dependence of the dynamic coefficient of friction on the relative velocity of grain material layers are presented in the form of tables 2-4 and figures 4-7. The graphs of a function $k=f(V)$ presented in the record $y=f(x)$. 
Table 2.Static and dynamic friction coefficients for wheat.

\begin{tabular}{|r|r|r|r|r|r|r|r|r|}
\hline Test & $\mathrm{n}, \mathrm{min}^{-1}$ & $\mathrm{Y}, \mathrm{H}$ & $\mathrm{y}, \mathrm{H}$ & $\mathrm{T}, \mathrm{H}$ & $\mathrm{F}, \mathrm{H}$ & $\mathrm{V}, \mathrm{m} / \mathrm{s}$ & $\mathrm{k}$ & $\varphi$, degree \\
\hline 1 & 0 & 2,30 & 0,90 & 1,40 & 2,52 & 0 & 0,86 & 40,7 \\
\hline 2 & 108 & 2,28 & 1,20 & 1,08 & 1,94 & 0,38 & 0,66 & 33,4 \\
\hline 3 & 190 & 2,64 & 1,24 & 1,40 & 2,52 & 0,66 & 0,86 & 40,7 \\
\hline 4 & 260 & 2,68 & 1,26 & 1,42 & 2,56 & 0,91 & 0,87 & 41,0 \\
\hline 5 & 320 & 2,75 & 1,28 & 1,47 & 2,65 & 1,12 & 0,90 & 42,0 \\
\hline 6 & 380 & 3,10 & 1,29 & 1,81 & 3,26 & 1,33 & 1,11 & 48,0 \\
\hline 7 & 444 & 3,31 & 1,31 & 2,00 & 3,60 & 1,55 & 1,22 & 50,7 \\
\hline 8 & 500 & 3,30 & 1,32 & 1,98 & 3,56 & 1,75 & 1,21 & 50,4 \\
\hline 9 & 560 & 4,10 & 1,32 & 2,78 & 5,00 & 1,95 & 1,70 & 59,5 \\
\hline 10 & 616 & 4,25 & 1,33 & 2,92 & 5,26 & 2,15 & 1,79 & 60,8 \\
\hline 11 & 680 & 4,63 & 1,34 & 3,29 & 5,92 & 2,37 & 2,01 & 63,5 \\
\hline 12 & 720 & 5,14 & 1,35 & 3,79 & 6,82 & 2,51 & 2,32 & 66,7 \\
\hline
\end{tabular}

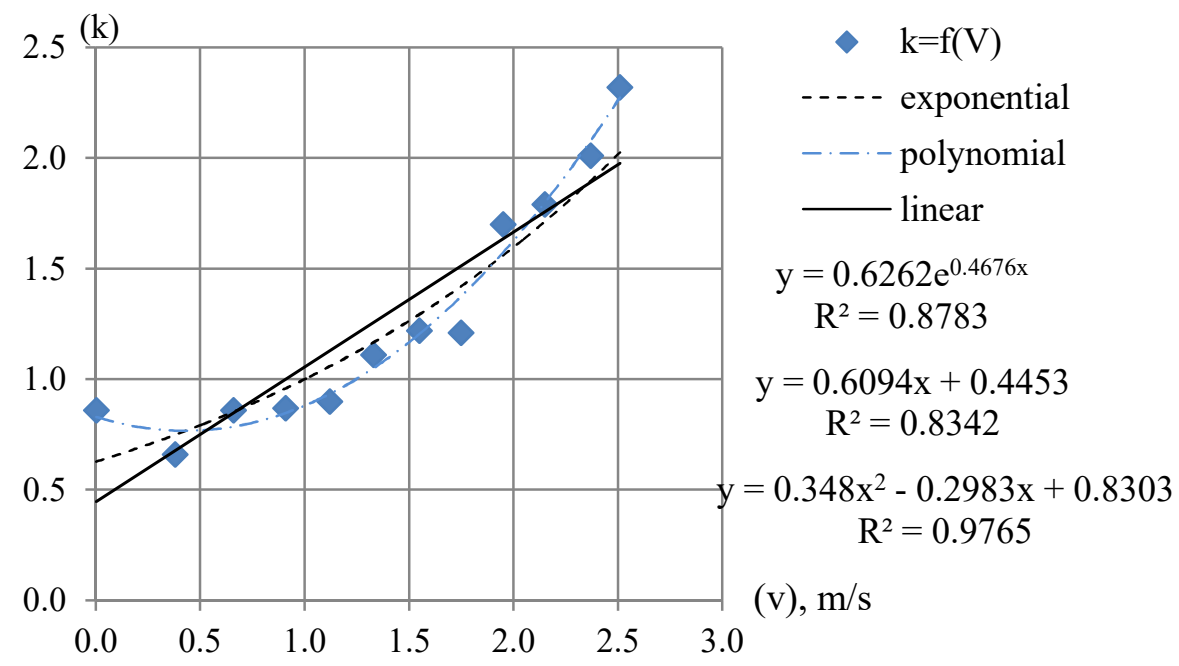

Fig. 4.Dependence of the dynamic coefficient of friction on the relative velocity of the layers of wheat.

Table 3. Static and dynamic friction coefficients for barley.

\begin{tabular}{|r|r|r|r|r|r|r|c|r|}
\hline Test & $\mathrm{n}, \mathrm{min}^{-1}$ & $\mathrm{Y}, \mathrm{H}$ & $\mathrm{y}, \mathrm{H}$ & $\mathrm{T}, \mathrm{H}$ & $\mathrm{F}, \mathrm{H}$ & $\mathrm{V}, \mathrm{m} / \mathrm{s}$ & $\mathrm{k}$ & $\varphi$, degree \\
\hline 1 & 0 & 1,90 & 0,90 & 1,00 & 1,80 & 0 & 0,73 & 36,1 \\
\hline 2 & 112 & 2,53 & 1,20 & 1,33 & 2,39 & 0,39 & 0,98 & 44,4 \\
\hline 3 & 190 & 2,85 & 1,24 & 1,61 & 2,90 & 0,66 & 1,18 & 49,7 \\
\hline 4 & 254 & 2,84 & 1,26 & 1,58 & 2,84 & 0,89 & 1,16 & 49,2 \\
\hline 5 & 314 & 3,13 & 1,28 & 1,85 & 3,33 & 1,10 & 1,36 & 53,7 \\
\hline 6 & 370 & 3,62 & 1,29 & 2,33 & 4,19 & 1,29 & 1,71 & 59,7 \\
\hline 7 & 432 & 3,90 & 1,30 & 2,60 & 4,68 & 1,51 & 1,91 & 62,4 \\
\hline 8 & 500 & 4,50 & 1,32 & 3,18 & 5,72 & 1,75 & 2,33 & 66,8 \\
\hline 9 & 560 & 4,67 & 1,32 & 3,35 & 6,03 & 1,95 & 2,46 & 67,9 \\
\hline 10 & 620 & 5,35 & 1,33 & 4,02 & 7,24 & 2,16 & 2,96 & 71,3 \\
\hline
\end{tabular}




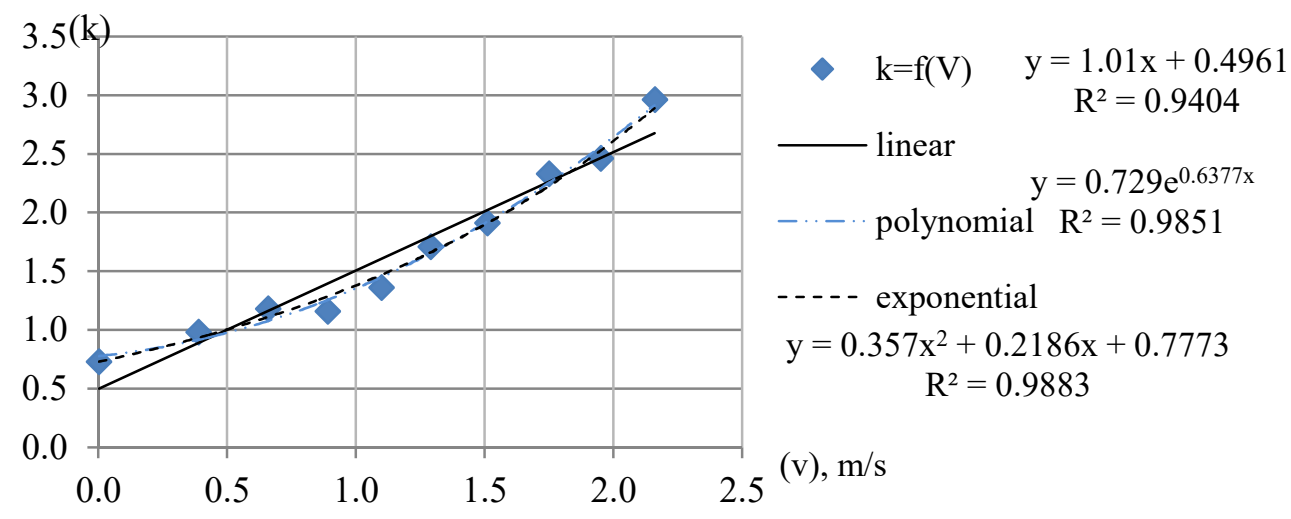

Fig. 5.Dependence of the dynamic coefficient of friction on the relative velocity of moving layers of barley.

Table 4. Static and dynamic friction coefficients for sunflower.

\begin{tabular}{|r|r|r|r|r|r|r|r|r|}
\hline Test & $\mathrm{n}, \mathrm{min}^{-1}$ & $\mathrm{Y}, \mathrm{H}$ & $\mathrm{y}, \mathrm{H}$ & $\mathrm{T}, \mathrm{H}$ & $\mathrm{F}, \mathrm{H}$ & $\mathrm{V}, \mathrm{m} / \mathrm{s}$ & $\mathrm{k}$ & $\varphi$, degree \\
\hline 1 & 0 & 1,36 & 0,90 & 0,46 & 0,83 & 0 & 0,53 & 27,9 \\
\hline 2 & 108 & 2,15 & 1,20 & 0,95 & 1,71 & 0,38 & 1,09 & 47,5 \\
\hline 3 & 200 & 2,28 & 1,24 & 1,04 & 1,87 & 0,70 & 1,19 & 50,0 \\
\hline 4 & 266 & 2,30 & 1,27 & 1,03 & 1,85 & 0,93 & 1,18 & 49,7 \\
\hline 5 & 326 & 2,45 & 1,28 & 1,17 & 2,11 & 1,14 & 1,34 & 53,3 \\
\hline 6 & 370 & 2,57 & 1,29 & 1,28 & 2,30 & 1,29 & 1,46 & 55,6 \\
\hline 7 & 440 & 2,82 & 1,31 & 1,51 & 2,72 & 1,54 & 1,73 & 60,0 \\
\hline 8 & 514 & 3,45 & 1,32 & 2,13 & 3,83 & 1,79 & 2,44 & 67,7 \\
\hline 9 & 560 & 3,79 & 1,32 & 2,47 & 4,45 & 1,95 & 2,83 & 70,5 \\
\hline 10 & 624 & 3,88 & 1,33 & 2,55 & 4,59 & 2,18 & 2,92 & 71,1 \\
\hline 11 & 680 & 4,57 & 1,34 & 3,23 & 5,81 & 2,37 & 3,70 & 74,9 \\
\hline 12 & 750 & 4,62 & 1,35 & 3,27 & 5,89 & 2,62 & 3,75 & 75,1 \\
\hline
\end{tabular}

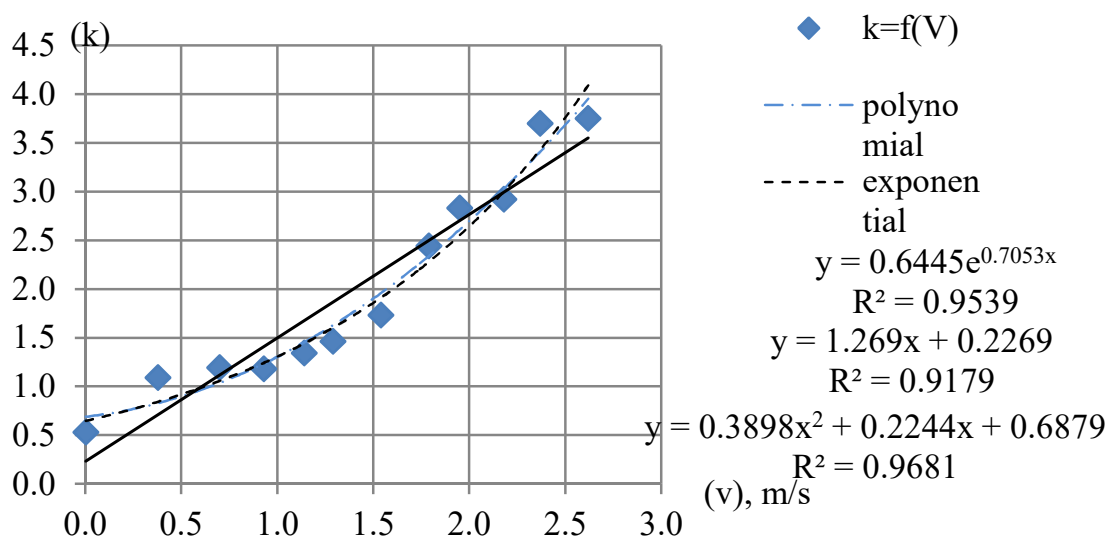

Fig. 6. Dependence of the dynamic coefficient of friction on the relative velocity of the sunflower layers. 
Table 5. Static and dynamic friction coefficients for safflower.

\begin{tabular}{|r|r|r|r|r|r|r|c|r|}
\hline Test & $\mathrm{n}, \mathrm{min}^{-1}$ & $\mathrm{Y}, \mathrm{H}$ & $\mathrm{y}, \mathrm{H}$ & $\mathrm{T}, \mathrm{H}$ & $\mathrm{F}, \mathrm{H}$ & $\mathrm{V}, \mathrm{m} / \mathrm{s}$ & $\mathrm{k}$ & $\varphi$, degree \\
\hline 1 & 0 & 1,60 & 0,90 & 0,70 & 1,26 & 0 & 0,71 & 35,4 \\
\hline 2 & 130 & 2,50 & 1,21 & 1,29 & 2,32 & 0,45 & 1,31 & 52,6 \\
\hline 3 & 200 & 2,35 & 1,24 & 1,11 & 2,00 & 0,70 & 1,13 & 48,5 \\
\hline 4 & 264 & 2,40 & 1,26 & 1,14 & 2,05 & 0,92 & 1,16 & 49,2 \\
\hline 5 & 320 & 2,40 & 1,28 & 1,12 & 2,02 & 1,12 & 1,14 & 48,7 \\
\hline 6 & 390 & 2,70 & 1,30 & 1,40 & 2,52 & 1,36 & 1,42 & 54,8 \\
\hline 7 & 450 & 2,90 & 1,31 & 1,59 & 2,86 & 1,57 & 1,62 & 58,3 \\
\hline 8 & 510 & 3,07 & 1,32 & 1,75 & 3,15 & 1,78 & 1,78 & 60,7 \\
\hline 9 & 580 & 3,28 & 1,33 & 1,95 & 3,51 & 2,02 & 1,98 & 63,2 \\
\hline 10 & 624 & 3,33 & 1,33 & 2,00 & 3,60 & 2,18 & 2,03 & 63,8 \\
\hline 11 & 690 & 3,46 & 1,34 & 2,12 & 3,82 & 2,41 & 2,16 & 65,2 \\
\hline 12 & 750 & 3,45 & 1,35 & 2,10 & 3,78 & 2,62 & 2,14 & 65,0 \\
\hline 13 & 800 & 4,20 & 1,35 & 2,85 & 5,13 & 2,79 & 2,90 & 71,0 \\
\hline
\end{tabular}

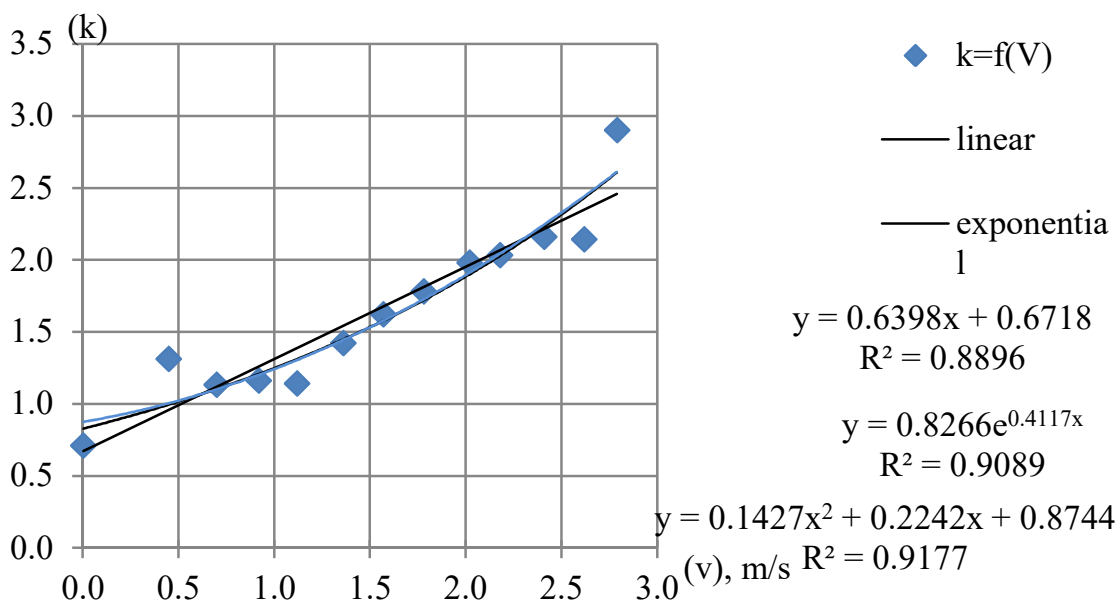

Figure 7.Dependence of the dynamic coefficient of friction on the relative velocity of the safflower layers.

\section{Conclusions}

1. The dependence of the dynamic coefficient of friction on the velocity is nonlinear. The values of $\mathrm{k}$ for all materials that are closest to the real data together give polynomial models of the second order. At the same time, exponential models also have a high degree of adequacy.

The generalized results of the experiments are presented in the table:

\begin{tabular}{|l|l|l|l|}
\hline Material & \multicolumn{1}{|c|}{ Polynomial model } & Exponential model & Range of speeds, $\mathrm{m} / \mathrm{s}$ \\
\hline Wheat & $\begin{array}{l}\mathrm{k}=0,348 \mathrm{~V}^{2}-0,298 \mathrm{~V}+0,830 \\
\mathrm{R}^{2}=0,976\end{array}$ & $\begin{array}{l}\mathrm{k}=0,626 \mathrm{e}^{0,467 \mathrm{~V}} \\
\mathrm{R}^{2}=0,878\end{array}$ & $0 \ldots 2,51$ \\
\hline Barley & $\begin{array}{l}\mathrm{k}=0,357 \mathrm{~V}^{2}+0,218 \mathrm{~V}+0,777 \\
\mathrm{R}^{2}=0,988\end{array}$ & $\begin{array}{l}\mathrm{k}=0,729 \mathrm{e}^{0,637 \mathrm{~V}} \\
\mathrm{R}^{2}=0,985\end{array}$ & $0 \ldots 2,16$ \\
\hline Sunflower & $\mathrm{k}=0,389 \mathrm{~V}^{2}+0,224 \mathrm{~V}+0,687$ & $\mathrm{k}=0,644 \mathrm{e}^{0,705 \mathrm{~V}}$ & $0 \ldots 2,62$ \\
\hline
\end{tabular}




\begin{tabular}{|l|l|l|l|}
\hline & $\mathrm{R}^{2}=0,968$ & $\mathrm{R}^{2}=0,953$ & \\
\hline Safflower & $\mathrm{k}=0,142 \mathrm{~V}^{2}+0,224 \mathrm{~V}+0,874$ & $\mathrm{k}=0,826 \mathrm{e}^{0,41 \mathrm{IV}}$ & $0 \ldots 2,79$ \\
& $\mathrm{R}^{2}=0,917$ & $\mathrm{R}^{2}=0,908$ & \\
\hline
\end{tabular}

2. The device of carousel type for determination of frictional characteristics of bulk materials allows to score problems of practical determination of dynamic coefficients of friction of the investigated bulk products of agricultural production in the range of speeds from 0 to $2,79 \mathrm{~m} / \mathrm{s}$ with reliability $\mathrm{R}^{2}$ not lower then 0,878 .

3. The carousel-type device for determining the frictional characteristics of bulk materials provides an opportunity to determine in practice such an important indicator of the physical and mechanical characteristics of bulk masses as the coefficient of friction, so it has practical application for specialists in the field of tribology, as well as engineers engaged in the design and operation of appropriate processing equipment

\section{References}

1. A. Doroshenko, MATEC Web of Conferences, 224, 05023 (2018)

2. D. Savenkov, MATEC Web of Conferences, 224, 05023 (2018)

3. X. Liu, Journal of Materials Science \& Technology, 35, 1412-1421 (2019)

4. H. Baek, International Journal of Solids and Structures, 144-145, 86-99 (2018)

5. C. Menapace, Wear, 398-399, 191-200 (2018)

6. K. Saw, Materailstoday: processing, 5, 24094-24103 (2018)

7. K. Senetakis, Tribology International, 111, 1-8 (2017)

8. A. Vakis, Tribology International, 125, 169-199 (2018)

9. S. Zhang, Materailstoday (2018)

10. U. Nirmal, Tribology International, 83, 77-104 (2015)

11. T. Mills, Woodhead Publishing Series in Food Science, Technology and Nutrition, 292309 (2013)

12. B. Winkeljann, Biotribology, 14, 11-18 (2018)

13. P. Udaykant, Tribology International, 126, 240-248 (2018)

14. Yu.A. Ivanov, MATEC Web of Conferences, 224, 05023 (2018)

15. S.I. Kambulov, MATEC Web of Conferences, 224, 05022 (2018) 